\title{
Analysis of the Relation between Particle Matter Concentration and Meteorological Parameter at Montevideo City
}

\author{
José Cataldo, Alice Elizabeth González \\ Instituto de Mecánica de los Fluidos e Ingeniería Ambiental, Facultad de Ingeniería, Universidad de la República, \\ Montevideo, Uruguay \\ Email: jcataldo@fing.edu.uy
}

How to cite this paper: Cataldo, J. and González, A.E. (2018) Analysis of the Relation between Particle Matter Concentration and Meteorological Parameter at Montevideo City. Open Journal of Air Pollution, 7 , 120-139.

https://doi.org/10.4236/ojap.2018.72007

Received: April 2, 2018

Accepted: June 11, 2018

Published: June 14, 2018

Copyright $\odot 2018$ by authors and Scientific Research Publishing Inc. This work is licensed under the Creative Commons Attribution International License (CC BY 4.0).

http://creativecommons.org/licenses/by/4.0/ (c) (i) Open Access

\begin{abstract}
We present an analysis of particle matter (MP) concentration measured at three stations located in the department of Montevideo, Uruguay. The Montevideo Council and the National Directorate of the Environment of Uruguay are interested in analyzing the possibility of predicting unsettling air quality events by other means not directly related to build and operate a real time air quality monitoring network. A strong correlation between measurements in different air quality stations especially along events of high concentration was obtained; it is intended to be associated with a distributed source. In such cases, high correlation was also found between the pollutant concentration and the meteorological variables temperature, wind velocity and mixing layer depth. As there is no air quality available data in real time, an accurate prediction of meteorological variables seems to be a good option for properly forecasting of air quality in Montevideo city, especially in terms of MP concentrations.
\end{abstract}

\section{Keywords}

Air Quality, Particle Matter Pollution, Atmospheric Boundary Layer

\section{Introduction}

Montevideo is located on the Rio de la Plata shore in southern Uruguay. A windy climate confers to the city a healthy atmospheric environment. However, in recent years, several events with high atmospheric pollutant concentration (especially particulate matter) have occurred.

The Environmental Quality and Control Evaluation Service of the Montevideo 
Council have an air quality monitoring network that measures meteorological parameters and pollutant concentrations. The National Administration of Power Plants and Electrical Transmissions (UTE) and the National Oil Company (ANCAP) operate monitoring stations that make up the aforementioned network. The air quality monitoring network of Montevideo does not operate on line; when most frequently, data is obtained once a week.

The aforementioned events were registered in all the stations of this network.

The Montevideo Council is interested in the forecast of these events to develop management actions as to minimize effects on the population. To proceed with the developing of a forecast, significant variables must be identified. High pollutant concentration events could be linked to high emissions of normally operating facilities, high emissions in abnormal conditions of facilities and given meteorological conditions; some pollutant sources depend on meteorological variables such as the domestic heating. Segura et al., 2013 [1] analyzed this kind of relationships. For effectively forecasting high pollutant concentration events, meteorological forecasts of significance parameters must be done.

There are several tools to proceed with the meteorological forecast, which are typically applied to analyze climate evolution, wind-power production and to determine adequate times for crop harvesting. These tools are based on the downscaling of climatic data using numerical model as the Weather Research and Forecasting (WRF, Skamarock, 2008 [2]; Gutiérrez et al., 2013 [3]). In each case, significant meteorological parameters must be predicted to produce a useful forecast. Along with a meteorological prediction, knowledge about the operation of different emission sources should be used to obtain an effective forecast.

The pollution situations occurrence depends on the properties of the pollutant emission sources. Each source has its own characteristics as geometry, superficial distribution, kind and rate of pollutant released, thermodynamic characteristics and its operation dependence on meteorological parameters.

Also, the presence of different pollutant sources depends on issues as energetic policy, air quality policy or land ordering. Domestic heating by burning wood could be quoted as an example. In Argentine where the natural gas heating is widely used, the wood is less frequent than in Chile and Uruguay where is one of the main fuels for household heating.

In the first stage of producing a forecast, we carried out an analysis aimed to identify correlations between pollutant concentrations and meteorological parameters, as to identify the effect of relevant pollutant sources as it is analyzed in Grange et al., 2013 [4]. This analysis is based on the results of the measurements of the monitoring network as it also is presented in Dogerrà et al., 2010 [5]. Alternatively, we could use a tool as WRF previously calibrated with local data.

The aim of this paper is to introduce a first step of a methodology to forecast critical air pollution situations. The Montevideo city case is presented as a worked example. Once the Council of Montevideo knew the results presented in this paper, a project was launched to set up an operative forecasting of high 
concentration particle matter events.

\section{Significant Parameter Characterization for the Dispersion of Atmospheric Pollutant}

The atmospheric flow transports, diffuses and mix the pollutants released into the atmosphere. Different meteorological forcing with diverse action scales such as synoptic, meso and micro meteorological scales produce this atmospheric flow. As an example of meteorological forcing, in Uruguay include semi-permanent cyclone and anti-cyclone systems, marine-land breeze and mountain-valley winds. In addition, some micro scale factors are to be considered, as the change of roughness ground, presence of hills and changes of ground temperatures associated with the transition from sea to land. Ahrens, 1999 [6]; Arya, 1999 [7]; Plate, 1982 [8]; Pedlosky, 1987 [9] and Holton, 2004 [10] described different characteristics of such meteorological forcing.

The evolution of the different meteorological scale forcing, at one site along the time, determines the particular climate in such site. Meteorological parameters such as wind velocity, wind direction, turbulence, temperature and absolute humidity will have different distributions at different altitudes for each meteorological forcing; cloudiness will also be different in each case.

A turbulent flow with a higher turbulence level, will produce a faster dispersion and will disperse in a shorter distance from the pollutant release than a less turbulent flow. In atmospheric flows, the turbulence production is associated to two different processes. The first one is the mechanical process, associated to the strain rate of the flow linked to the wind velocity, the roughness of the soil and the geometry of obstacles. The second one is the thermodynamic process, associated to the temperature gradient. The thermodynamic process can produce turbulence if the atmosphere is UNSTABLE (temperature gradient is lower than the adiabatic gradient) or dampening of turbulence if the atmosphere is STABLE (temperature gradient is greater than the adiabatic gradient). Instances of UNSTABLE atmospheric conditions typically occur during the daytime while STABLE conditions usually occur during the nighttime.

The local wind direction determines the pollutant transport direction. During high turbulence levels events, the flow strongly disperses the pollutant and then it dilutes the pollutant in a short distance from the release point, in downwind direction. When the atmosphere is STABLE, a mixing layer appears near the ground, where the flow is turbulent. Above this region, the stream is non-turbulent. If pollutants are released inside the mixing layer, they will be confined to this region. Lower mixing layers are related to smaller dilution volumes and higher pollutant concentrations should be expected.

\section{Field Experimental Equipment}

The development of the forecasting tool must be based on high quality data. A detailed zone description including wind exposure and main pollutant sources, the critical analysis of equipment operation and registration methodology are 
needed. In this case, the field equipment network used in this experiment was composed by air quality monitoring stations and meteorology monitoring stations.

\subsection{Air Quality Monitoring Network Station}

Montevideo network has three stations, as shown in Figure 1. La Teja station is managed by the oil company and it is compose by a beta particle counter model MP101M, a dioxide nitrogen measurement unit model AC32M based on quimioluminiscencia and a $\mathrm{SO}_{2}$ and TRS measurement unit model AF based in luminescence UV from Envrionment S.A. Colon and Palacio Legislativo stations are composed by a Carbon Monoxide Analyzer model M300EM, an UV Fluorescence $\mathrm{SO}_{2}$ analyzer model $100 \mathrm{E}$ and a Nitrogen Oxide Analyzer model 200E from Teledyne. Also, these stations include a Beta Gauge Method FRM Equivalent Particle Matter Monitor SPM-613F from Kimoto Electric. Table 1 presents the available data in each station.

Hourly mean concentrations for each air quality parameter were used to describe their evolution along time. In this paper only particle matter results are presented.

The first data-cleaning process included the elimination of a complete day when some hourly mean concentration was missing. This depuration was performed for each parameter separately to maintain longer time histories.

Table 2 presents the wind exposure conditions for each air quality monitoring station. Figures 2-4 and Table 3 present the most meaningful close emission sources; they are then summarized in Table 3. In Figures 2-4 the station location is indicated with a red dot.

Close to Station I (Figure 2), there is a power station powered by fuel oil (Batlle Power Station) and a residential zone.

Near Station II (Figure 3) there is an oil refinery as well as a neighborhood a few kilometers away where there are several tanneries in operation; large residential zones surround this station.

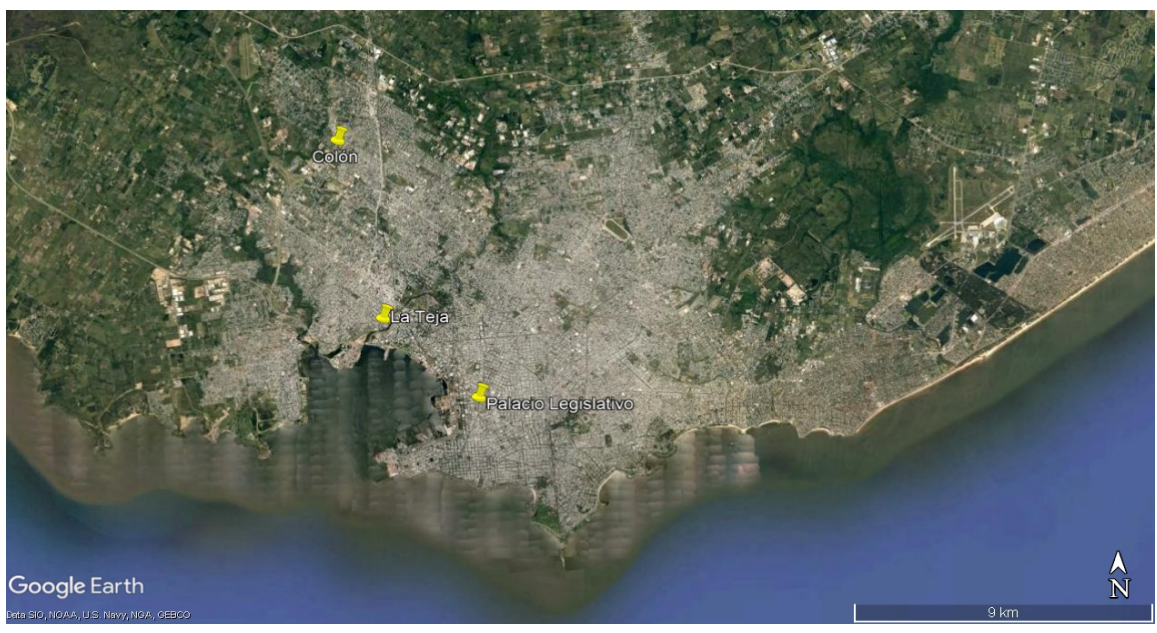

Figure 1. Air quality monitoring network (stations marked on a Google earth ${ }^{\circledast}$ image). 


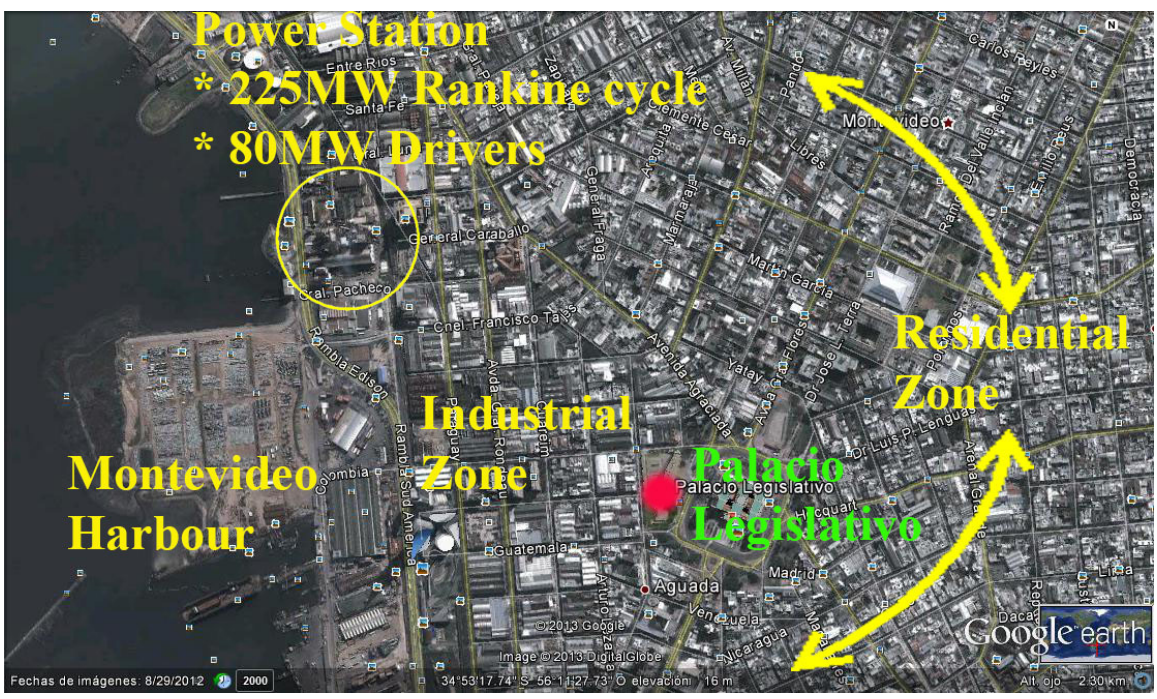

Figure 2. Emission sources around station I (built up on a Google earth ${ }^{\circledast}$ image).

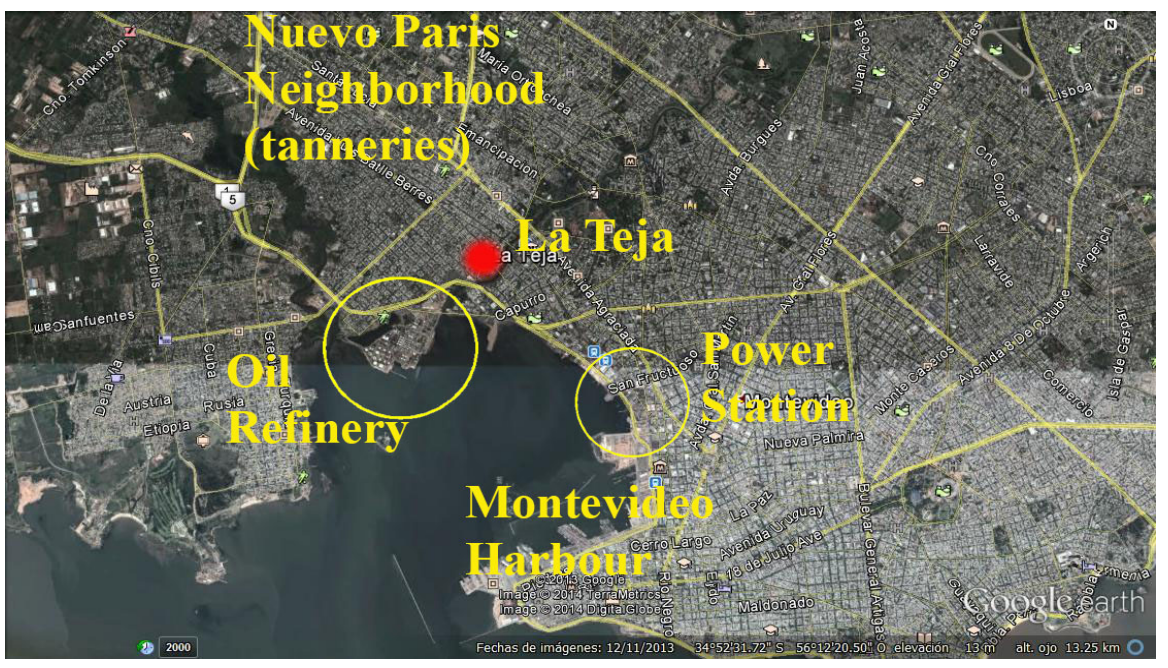

Figure 3. Emission sources around station II (built up on a Google earth ${ }^{\circledast}$ image).

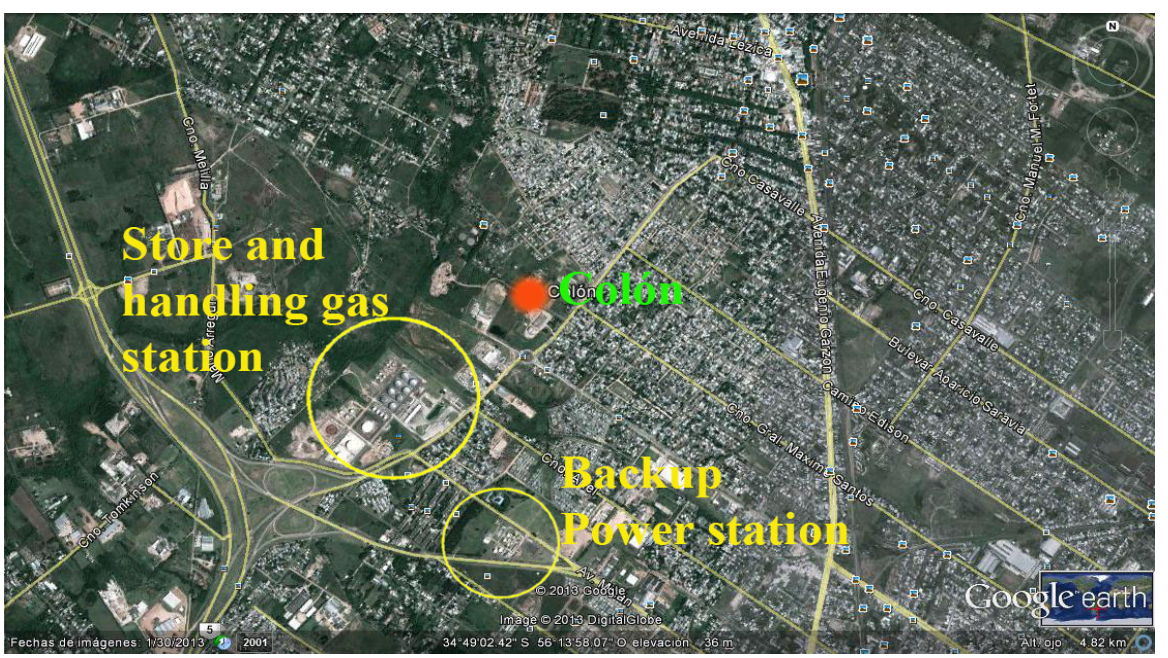

Figure 4. Emission sources around station III (built up on a Google earth ${ }^{\circledast}$ image). 
Table 1. Available data in each station $\left(\mathrm{CO}=\right.$ carbon monoxide; $\mathrm{SO}_{2}=$ sulfur dioxide; $\mathrm{NO}_{2}=$ nitrogen dioxide; $\mathrm{MP}_{10}=$ particulate matter of less than $10 \mu \mathrm{m} ; \mathrm{MP}_{2.5}=$ particulate matter of less than $2.5 \mu \mathrm{m}$; TRS = total reduced sulfur compounds).

\begin{tabular}{|c|c|c|c|c|c|c|c|c|}
\hline \multirow{2}{*}{ Station } & \multirow{2}{*}{\multicolumn{2}{|c|}{ Measurement time period }} & \multicolumn{6}{|c|}{ Pollutant concentration (units) } \\
\hline & & & $\mathrm{CO}$ & $\mathrm{SO}_{2}$ & $\mathrm{NO}_{2}$ & $\mathrm{MP}_{10}$ & $\mathrm{MP}_{2.5}$ & TRS \\
\hline $\begin{array}{c}\text { Palacio } \\
\text { Legislativo }\end{array}$ & $1 / 06 / 2010,0: 00$ & $21 / 12 / 2012,23: 00$ & ppm & $\mathrm{ppb}$ & ppb & $\mu \mathrm{g} / \mathrm{m}^{3}$ & $-\cdots$ & --- \\
\hline La Teja & $1 / 01 / 2012,1: 00$ & $31 / 12 / 2012,23: 00$ & $\mathrm{mg} / \mathrm{m}^{3}$ & $\mu \mathrm{g} / \mathrm{m}^{3}$ & $\mu \mathrm{g} / \mathrm{m}^{3}$ & $-\cdots$ & $\mu \mathrm{g} / \mathrm{m}^{3}$ & $\mu \mathrm{g} / \mathrm{m}^{3}$ \\
\hline Colón & $1 / 04 / 2009,4: 00$ & $31 / 12 / 2012,23: 00$ & ppm & $\mathrm{ppb}$ & $\mathrm{ppb}$ & $\mu \mathrm{g} / \mathrm{m}^{3}$ & ---- & ---- \\
\hline
\end{tabular}

Table 2. Wind exposure conditions of each air quality monitoring station.

\begin{tabular}{ccl}
\hline Ref. & \multicolumn{1}{c}{ Station } & \multicolumn{1}{c}{ Wind exposure } \\
\hline I & Palacio Legislativo & $\begin{array}{l}\text { Urban in all directions. For directions between SW and } \\
\text { NW, the sea is } 700 \mathrm{~m} \text { far. } \\
\text { Sea between E and SSW wind directions, and sub urban } \\
\text { in the rest of directions. } \\
\text { II }\end{array}$ \\
La Teja & Colón & $\begin{array}{l}\text { Rul between WSW and WNW wind directions and } \\
\text { urban in the rest. }\end{array}$ \\
\hline
\end{tabular}

Table 3. Surrounding of measurement stations.

\begin{tabular}{|c|c|c|c|}
\hline Ref. & Station & Wind exposure & Near emitting \\
\hline I & $\begin{array}{l}\text { Palacio } \\
\text { Legislativo }\end{array}$ & Urban & $\begin{array}{l}\text { Batlle Power Station, transit, distributed urban } \\
\text { emitting. }\end{array}$ \\
\hline II & La Teja & Sub-urban and Sea & $\begin{array}{l}\text { Oil Refinery, Montevideo Harbour, tanneries } \\
\text { neighborhood, transit, urban emitting. }\end{array}$ \\
\hline III & Colón & Sub-urban and Rural & CTR, Storage and gas-handling, traffic. \\
\hline
\end{tabular}

Near Station III (Figure 4), a storage and gas-handling station operates with gas from a pipe and refills tanks transported by trucks. A backup power station (CTR) powered by diesel is found near the station. A rural zone on the west and a suburban zone on the east encircle the station.

\subsection{Weather Station Network}

Three weather stations (red globes) were included in the network for the examination, they were located at: Montevideo harbor (ANP), air quality monitoring Station II (La Teja), and Carrasco airport (Carrasco). Figure 5 shows the location of these stations. Also, the air quality stations in yellow are included.

Table 4 illustrates the geographical coordinates as well as the aerodynamic and thermodynamic characteristics around each weather station.

The data in Table 4 were compiled from previous studies (Counihan, 1975 [11]; Hunt et al., 1982 [12]; Lewis, 1995 [13]).

\section{Weather Data Processing Methodology}

According to the data that were obtained in each weather station, the climate was characterized in each air quality monitoring station. If the climate 


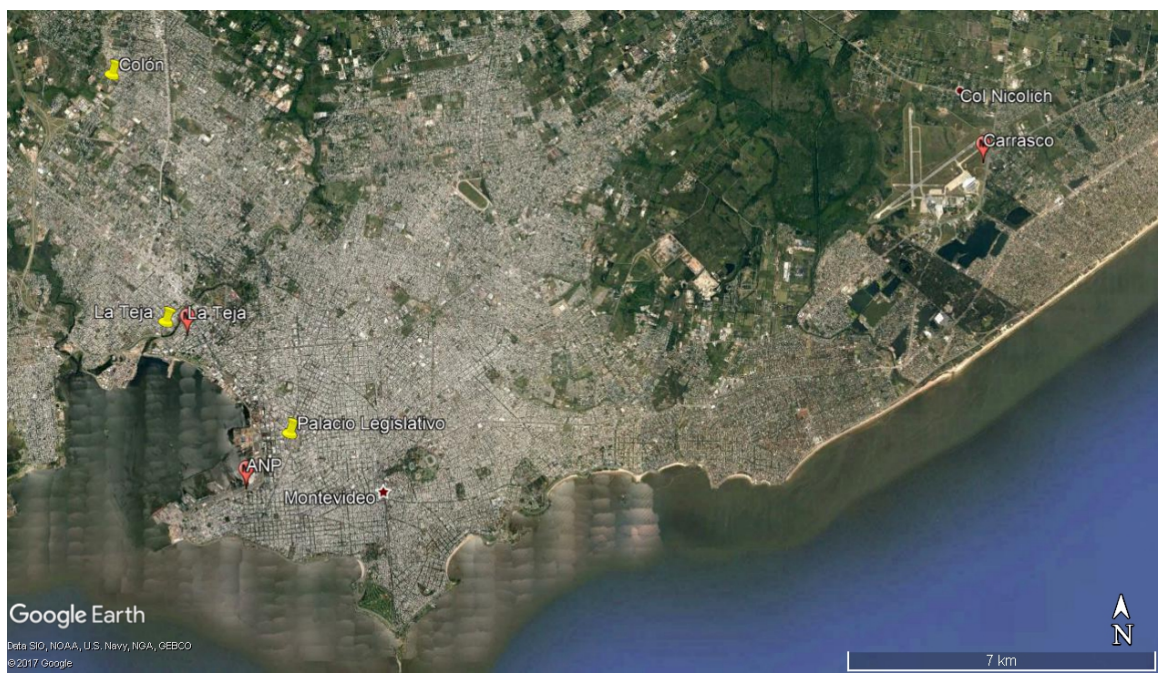

Figure 5. Weather station location (built up on a Google earth ${ }^{\circledast}$ image). Yellow marks: air quality monitoring stations; red marks: weather stations.

Table 4. Geographic, aerodynamic and thermodynamic characteristics surrounding each weather station.

\begin{tabular}{|c|c|c|c|c|c|c|c|}
\hline Station & Coordinates & Wind Directions & $\begin{array}{l}\text { Class of } \\
\text { terrain }\end{array}$ & $\begin{array}{l}\text { Roughness } \\
\text { length }(\mathrm{cm})\end{array}$ & $\begin{array}{l}\text { Zero displacement } \\
\text { plane height }(\mathrm{m})\end{array}$ & $\begin{array}{c}\text { Bowen } \\
\text { Ratio }\end{array}$ & $\begin{array}{c}\text { Albedo for } \\
\text { normal } \\
\text { incidence }\end{array}$ \\
\hline \multirow{2}{*}{ ANP } & $34^{\circ} 54^{\prime} 7.45^{\prime \prime S}$ & $0^{\circ}$ to $60^{\circ}, 260^{\circ}$ to $360^{\circ}$ & Sea & 1 & 0 & 0.15 & 0.07 \\
\hline & $56^{\circ} 12^{\prime} 20.27^{\prime \prime} \mathrm{W}$ & $60^{\circ}$ to $260^{\circ}$ & Urban & 200 & 15 & 1 & 0.46 \\
\hline \multirow{2}{*}{ La Teja } & $34^{\circ} 52^{\prime} 6.00^{\prime \prime}$ & $0^{\circ}$ to $110^{\circ}, 210^{\circ}$ to $360^{\circ}$ & Suburban & 100 & 0.6 & 1 & 0.46 \\
\hline & $56^{\circ} 13^{\prime} 15.00^{\prime \prime}$ & $110^{\circ}$ a $210^{\circ}$ & Sea & 1 & 0 & 0.15 & 0.07 \\
\hline \multirow{2}{*}{ Carrasco } & $34^{\circ} 49^{\prime} 58.36^{\prime \prime S}$ & All directions & Rural & 20 & 0 & & \\
\hline & $56^{\circ} 0^{\prime} 45.54^{\prime \prime} \mathrm{W}$ & & & & & & \\
\hline
\end{tabular}

surrounding the air quality stations of two sites could be assumed to be associated to the same synoptic meteorological forcing, then these sites would be considered to be "near". Momentum, heat and mass were parameterized according to this assumption.

The resulting data was used to determine the following parameters: sensible heat exchanges between air and ground $\left(Q_{s}\right)$, friction velocity $\left(u^{*}\right)$, mixing layer height $(h)$, Monin-Obhukov length scale $(L)$, roughness length $\left(Z_{0}\right)$, Bowen ratio $(B)$, albedo, wind speed $(U)$ and direction and temperature $(T)$. For each parameter, it was assumed that data gathering was performed every hour.

The network radiation heat $\left(Q_{I, \text { net }}\right)$ incident on the ground was calculated from radiation measurements obtained along the day time in La Teja station. During the night time, the network radiation heat loss was adjusted according to the reduction factor proposed by Kasten et al., (1980) [14].

$$
\text { Reduction Factor }=1-N^{3.4}
$$

where $N$ is the proportion of sky covered by clouds.

Assuming that the transmitted heat $\left(Q_{T}\right)$ is $10 \%$ of the incident radiation, we calculated the sensible heat exchanged with the soil $\left(Q_{S}\right)$ using Equation (2). 


$$
Q_{S}=\frac{0.9 Q_{I, n e t}}{1+1 / B}
$$

Monin-Obhukov length $(L)$ was estimated with the result from the latter equation for sensible heat $\left(Q_{s}\right)$, by using Equation (3).

$$
L=-\frac{T u^{* 3}}{k g\left(Q_{S} / \rho c_{p}\right)}
$$

In this equation, $k$ is the von Karman constant and $c_{p}$ the air specific heat in the atmospheric boundary layer up to $100 \mathrm{~m}$ or $120 \mathrm{~m}$ the relationship for wind speed adopted the modified logarithmic law (4).

$$
U(z)=\frac{u^{*}}{k}\left(\operatorname{Ln}\left(\frac{Z}{Z_{0}}\right)-\psi(Z / L)\right)
$$

As discussed by Arya (1999) [2], the function $\psi$ attains a different form which is related to the atmospheric stability. A similar relation is used for the temperature profile.

Knowing the velocity at a height $Z$ and the roughness length, we could infer the velocity friction and Monin-Obhukov length using the Equations (3) and (4).

Finally, we can guess the mixing layer height or the boundary layer height $(h)$ according to the results obtained by Arya (1999) [7] and Stull (2003) [15] which has shown the relation between the friction velocity, the Monin-Obhukov length, the Coriolis parameter and the temperature profile (Equation (5)).

$$
h \cong 0.4\left(u * \frac{L}{|f|}\right)^{1 / 2}
$$

The aforementioned methodology was used to produce time series of the significant meteorological parameters for each air quality measurement station.

The roughness length, the albedo for normal incidence and the Bowen rate were selected according to the surrounding terrain characteristics.

In this case, data for wind velocity, wind direction and temperature were obtained at La Teja station, while cloudiness data were obtained from the Carrasco station.

Figures 6-9 illustrate examples of the wind rose, the density probability curve of wind velocity, stability classes and the histogram of mixing layer height respectively deduced in one of the air quality monitoring station.

The mixing layer height values included in Figure 9 went as high as $600 \mathrm{~m}$. This ensemble of data comprised $43 \%$ of the total considered event. The remaining $57 \%$ of cases occurred at a mixing layer height over $600 \mathrm{~m}$.

\section{Identification of Particle Matter Concentration Evolution Patterns}

To identify the pattern of pollutant evolution, air quality and meteorological parameters were obtained to derive time series of simultaneous data. These time series were obtained for each air quality monitoring station. 


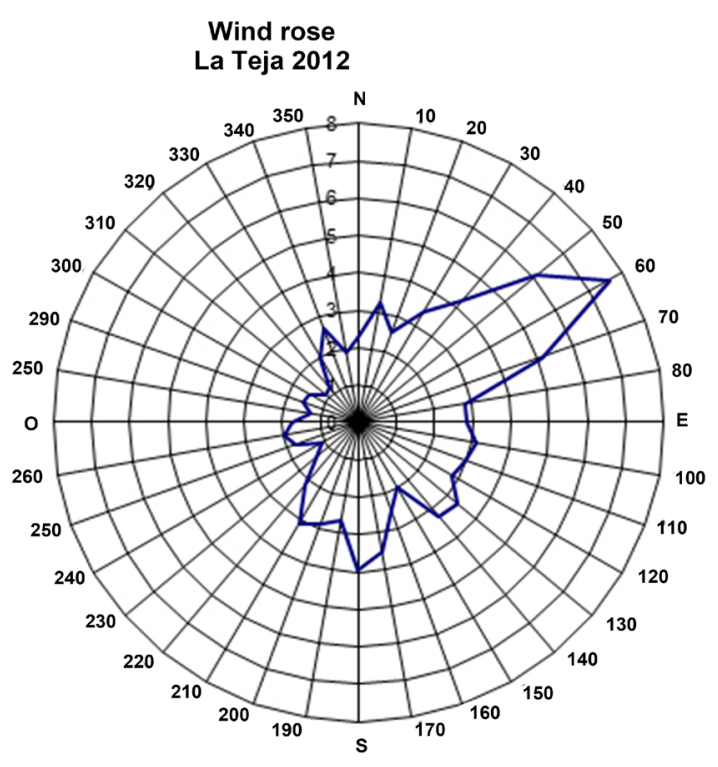

Figure 6. Wind rose, Station II, 2012.

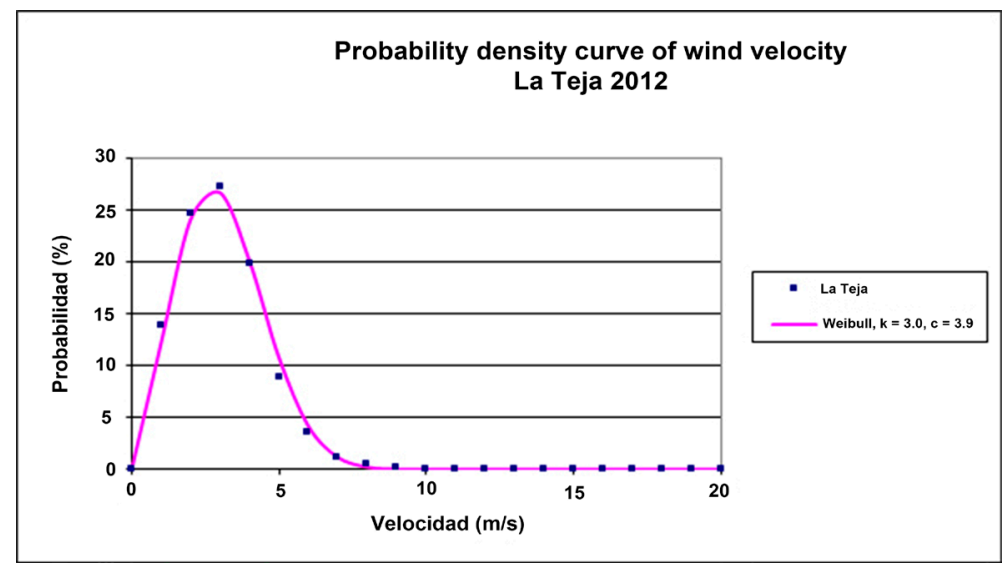

Figure 7. Probability density curve of wind velocity, Station II, 2012.

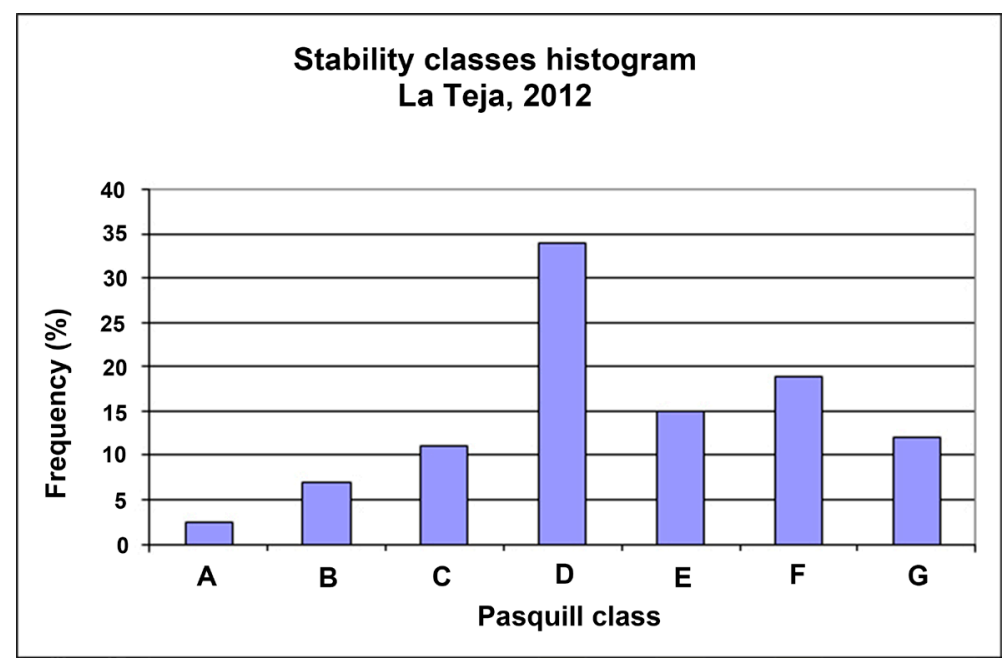

Figure 8. Histogram of stability classes, Station II, 2012. 


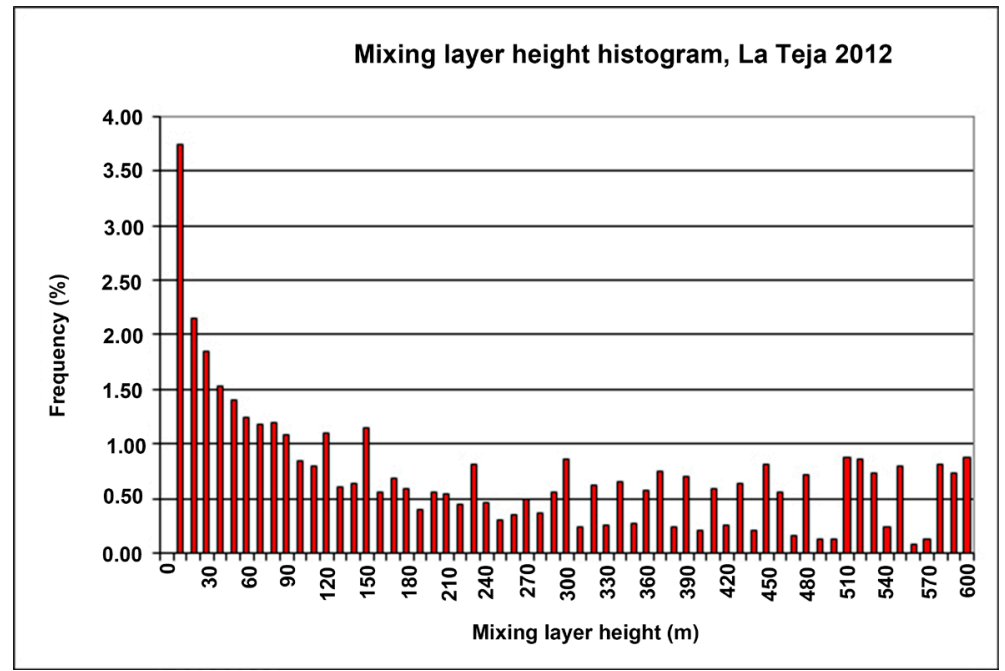

Figure 9. Histogram of mixing layer height, Station II, 2012.

Table 1 in Section 3.1 illustrates pollutant concentrations measured in each station. In this paper we concentrate the analysis on particle concentration. In Station I and III, pollutant matter was measured in terms of $\mathrm{MP}_{10}$, while in Station II it was measured in $\mathrm{MP}_{2.5}$. Both sizes of particles were analyzed jointly, as shown in the following analysis; these pollutants were identified as "particles".

Only the measurements along 2012 would be considered for the next analysis, since they presented simultaneous data in all stations with the longest period of data collection. Figures 10-12 show the daily concentration evolution for all stations during 2012.

A reference value of $150 \mu \mathrm{g} / \mathrm{m}^{3}$ for the daily average concentration of $\mathrm{MP}_{10}$, is shown in Figure 10 and Figure 11. It is the adopted value by GESTA Aire (Technical Working Group on Air Pollution Regulations), 2012 [16], The reference value of $35 \mu \mathrm{g} / \mathrm{m}^{3}$ included in Figure 12 for daily average concentration for $\mathrm{MP}_{2.5}$ is in adherence to a recommendation by EPA, 2011 [17], a target value obtained from the World Health Organization (OMS, 2005 [18]).

Several high concentration events are identified in the previous Figures 10-12 where the MP concentration evolution simultaneous for all stations; each high concentration event differed intensity. We identified six events in Stations I and III while only three in Station II. Station II was not operating during events A and $\mathrm{D}$ that were observed in the other stations.

For each event, the time evolution of the hourly mean concentration values was analyzed.

Figure 13 shows the time evolution of hourly mean concentrations along a six-day period for the three stations when event $\mathrm{C}$ occurred. Figure 14 reflects hourly mean concentrations during event B in a span of 48 hours. Figure 15 shows event D in a three-day time-frame but only for Stations I and III.

The hourly mean concentration values obtained at all three measuring stations exhibited a very strong correspondence. Taking into account that each station has different close emission sources, it is not possible to explain these events 


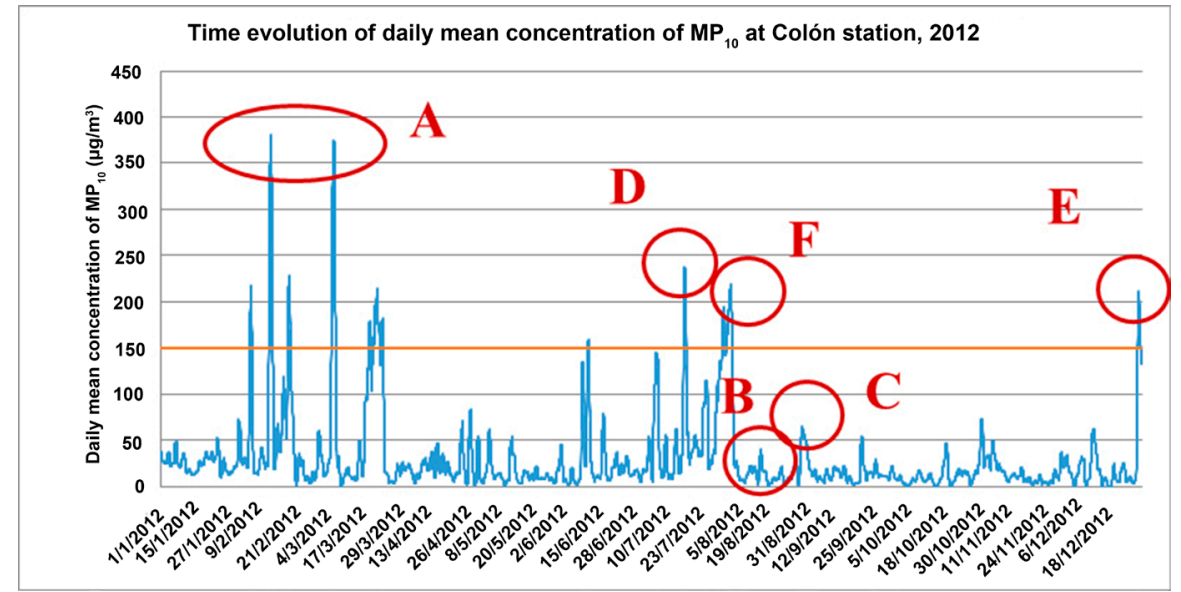

Figure 10. Time evolution of daily mean concentrations of $\mathrm{MP}_{10}$ at Station III in 2012.

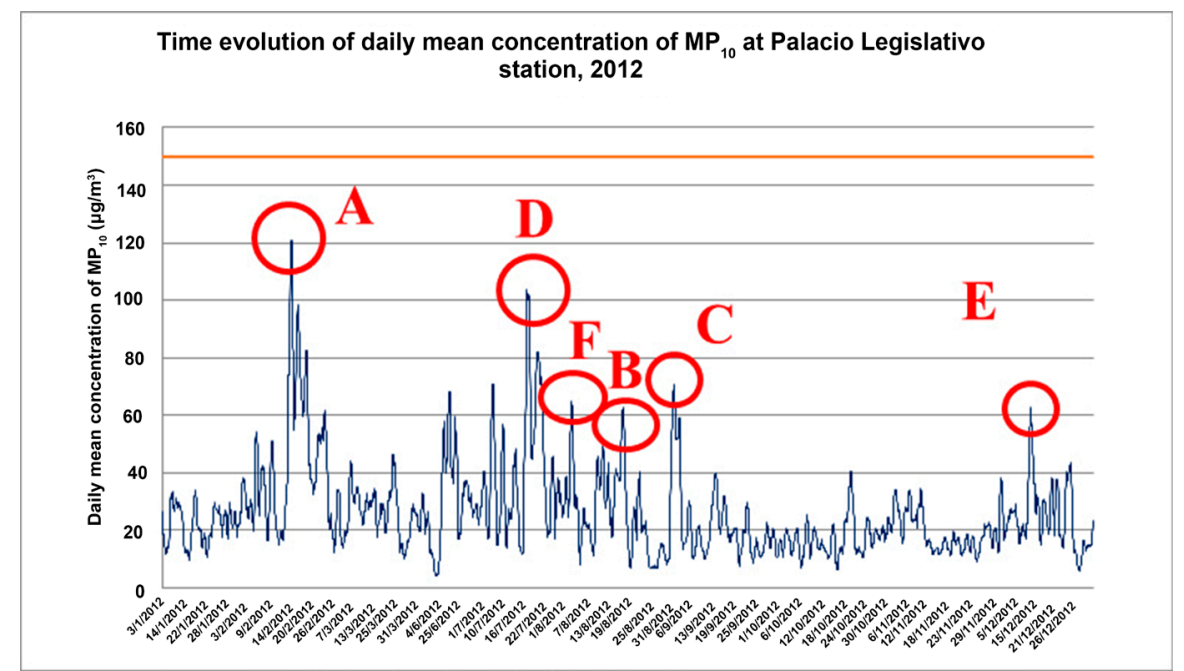

Figure 11. Time evolution of daily mean concentrations of $\mathrm{MP}_{10}$ at Station I, 2012.

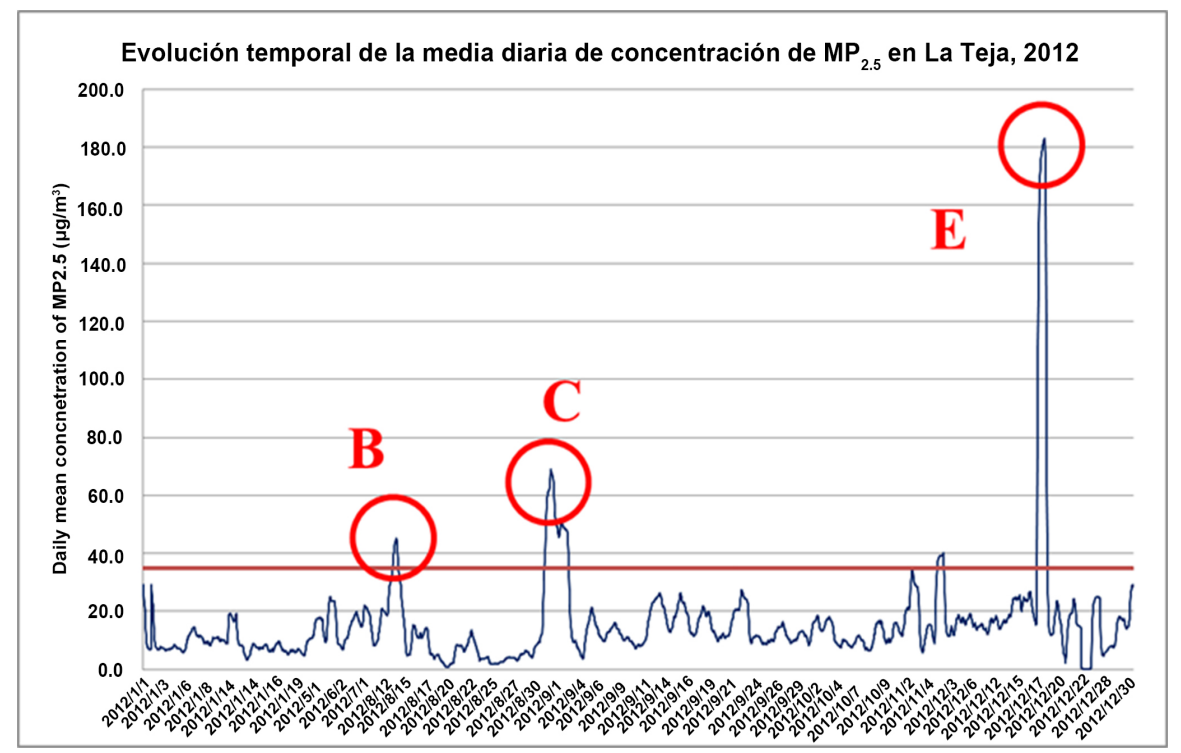

Figure 12. Time evolution of daily mean concentration of $\mathrm{MP}_{2.5}$ at Station II, 2012. 


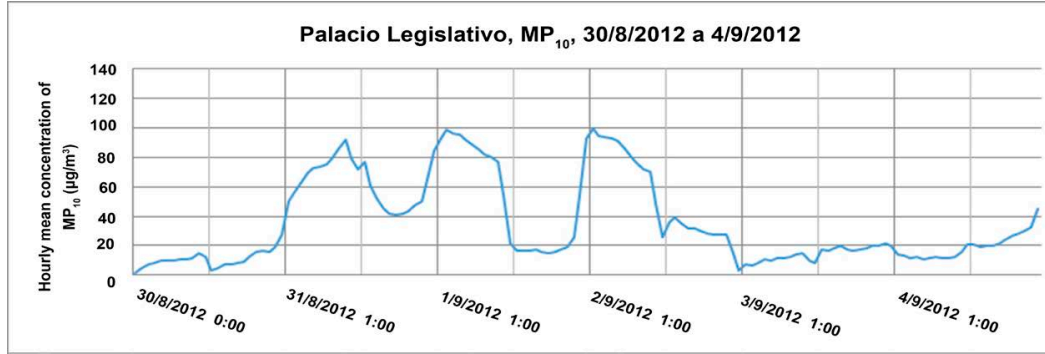

(a)

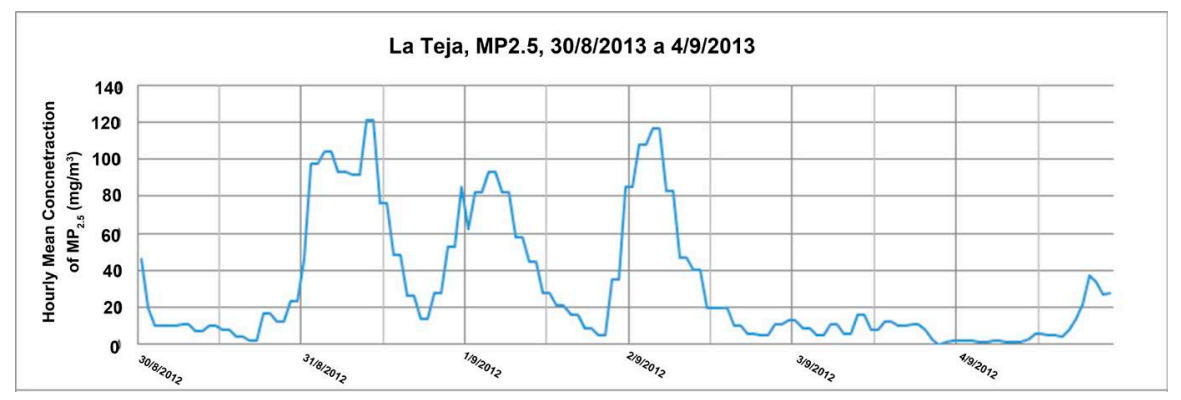

(b)

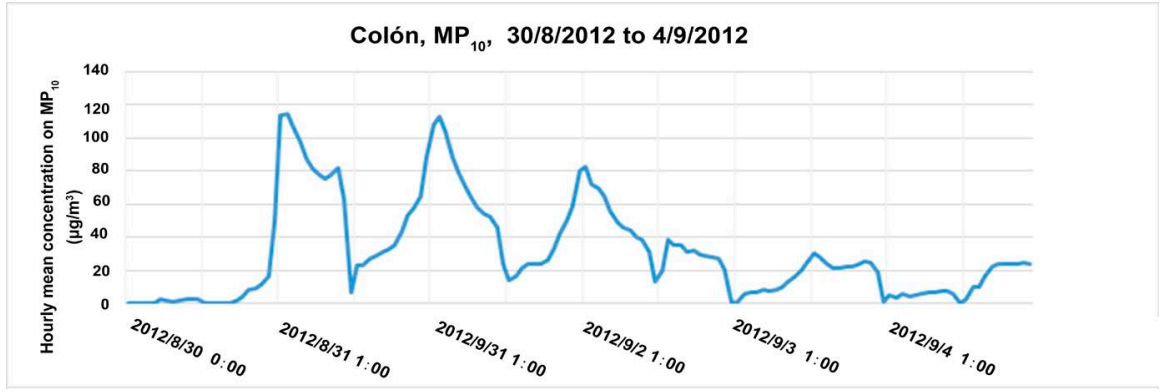

(c)

Figure 13. Evolution of hourly mean concentration of particles along event C (upper: Station I; middle: Station II; lower: Station III).

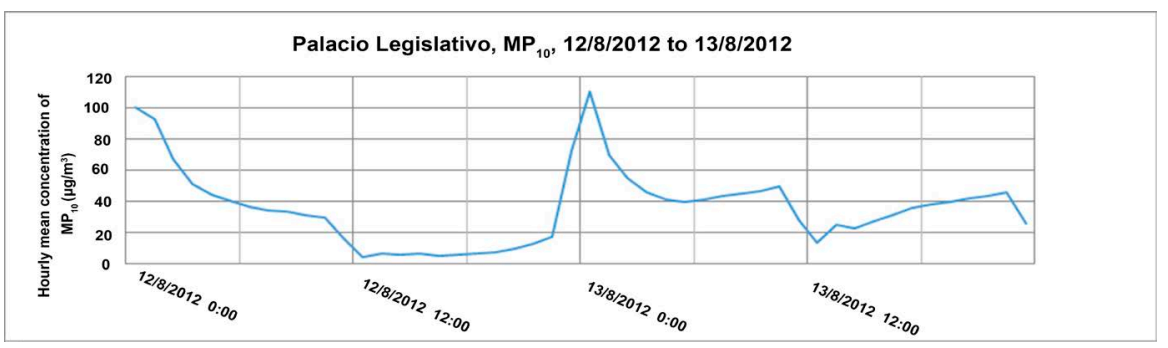

(a)

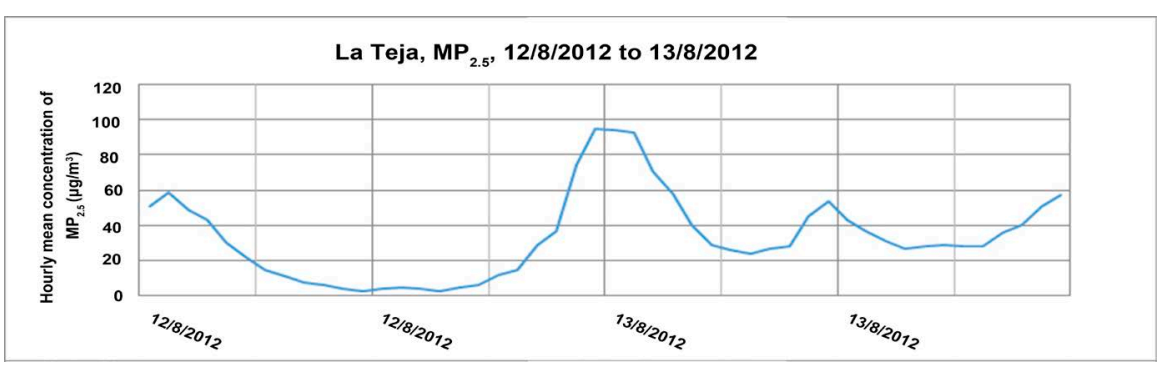

(b) 


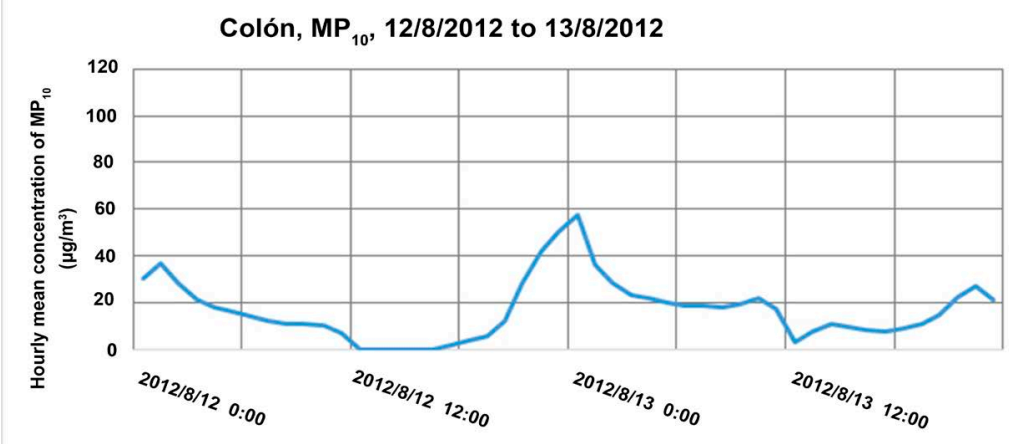

(c)

Figure 14. Evolution of hourly mean concentration of particle along event B (upper: Station I; middle: Station II; lower: Station III).

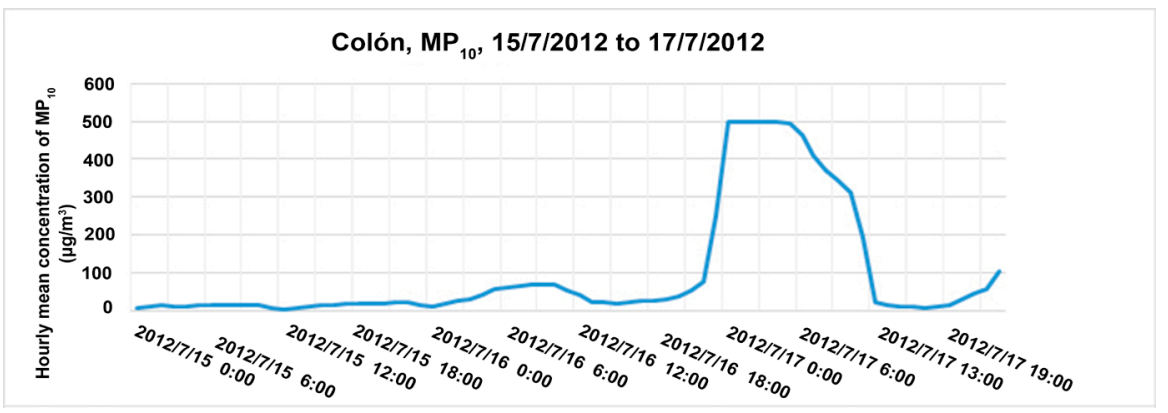

(a)

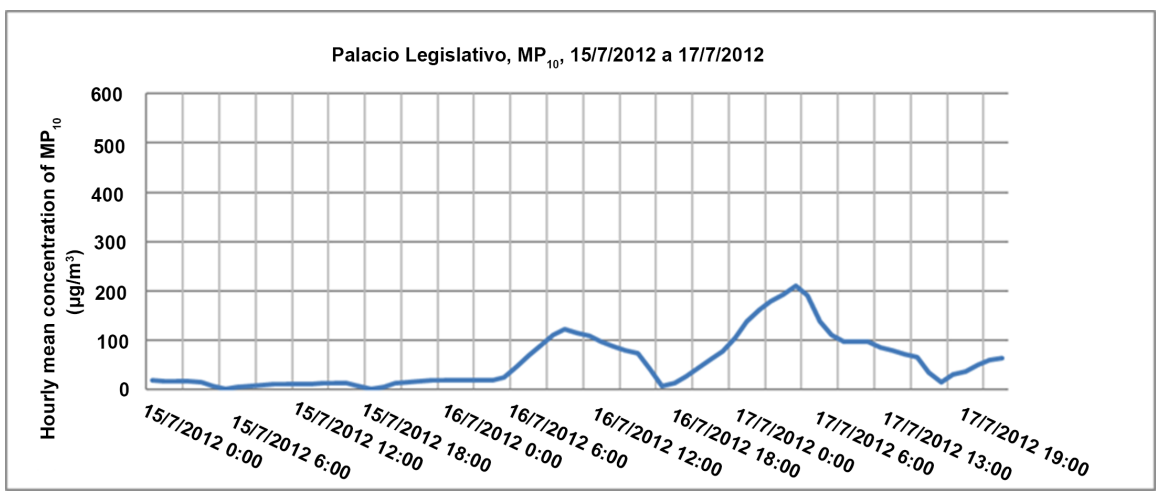

(b)

Figure 15. Evolution of hourly mean concentration of particle along event D (upper: Station III; lower: Station I).

only by those sources: to induce such a behavior, a process must have occurred across the department of Montevideo. Previous research experience of our team, as the presented in Inventario, 2010 [19], let us think about the incidence of particle matter emitted by domestic heating by burning wood in cold, calm and clear nights. We needed then to understand the phenomena to confirm this hypothesis.

To understand it, we decided to analyze the time evolution of meteorological parameters at different stations and the correlation coefficients between simultaneous data from pairs of air quality stations. 
We analyzed the correlation between the time series of MP concentration measured at the three environment stations. We took daily periods and for each day, we calculated the correlation coefficient between each pair of stations. Figure 16 shows the time evolution of these coefficients for all the period.

Figure 17 and Figure 18 show detailed sights of Figure 19 in the periods in which events with high particle matter concentration occur. The values of the correlation coefficient along these events are presented in Table 5.

Figure 19 shows the analysis of the time evolution of the three significant meteorological parameters, as temperature (a), wind velocity (b) and mixed layer depth (c), for the event that occurred from 30/8/20112 to 4/9/2012.

We also analyzed the time evolution of the three parameters during the other analyzed events as we show in Figure 20 and Figure 21 respectively; data was obtained for each event.

\section{Discussion}

The high MP concentration events showed in Figures 13-15 present the following characteristics:

- They were registered in every three monitoring stations of the air quality network.

- Temperature was lower than $13^{\circ} \mathrm{C}$.

- Wind velocity was less than $3 \mathrm{~m} / \mathrm{s}$.

- The mixed layer depth was not greater than $10 \mathrm{~m}$.

On the other hand, the events occurred for different atmospheric stability conditions.

When comparing data series, a strong correlation was found between the time evolutions series of particle concentrations measured in the three stations. In the near scale, each of the stations respond to different emission sources; then, the high concentrations events in the three stations need to have another explanation. In other words, this implies that the length scale of the pollutant source must be similar to the dimensions of the city.

These observations would lead to conclude that during low temperature periods, a distributed emission source starts up in Montevideo city. The pollutant source could be a consequence of domestic heating in lower temperatures. In agreement with the National Energetic Budget, wood has a very significance presence in domestic households. In Montevideo city, more than 72,000 Tons of

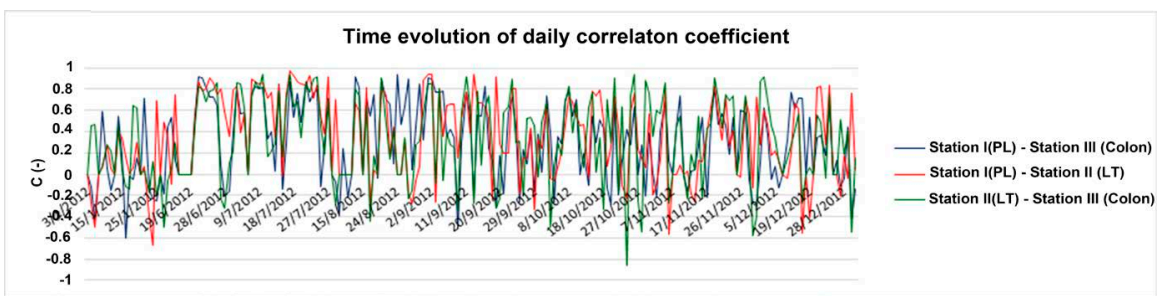

Figure 16. Time evolution of the daily correlation coefficient between pairs of air quality stations. 


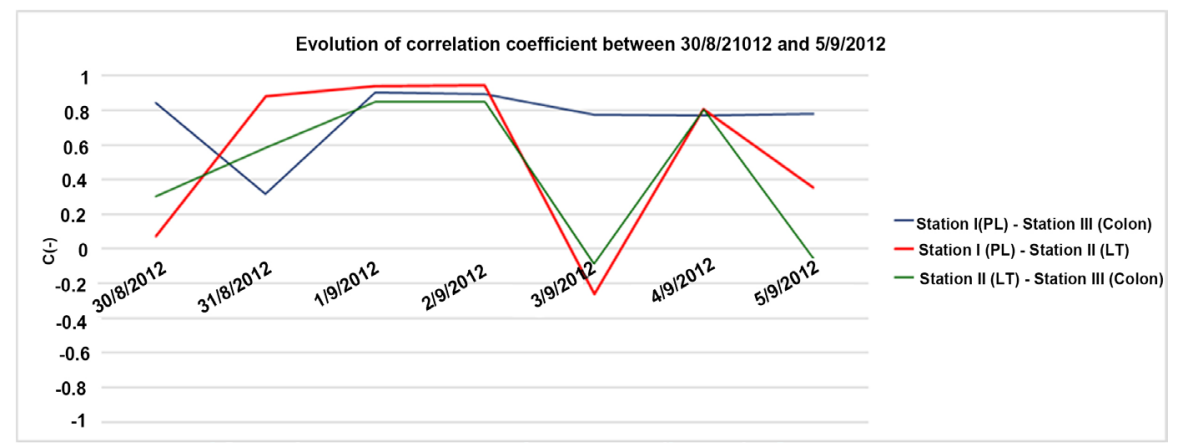

Figure 17. Time evolution of the correlation coefficients in the period between 30/8/2012 and 5/9/2012 (PL = Station I Palacio Legislativo; LT = Station II La Teja; Colón = Station III).

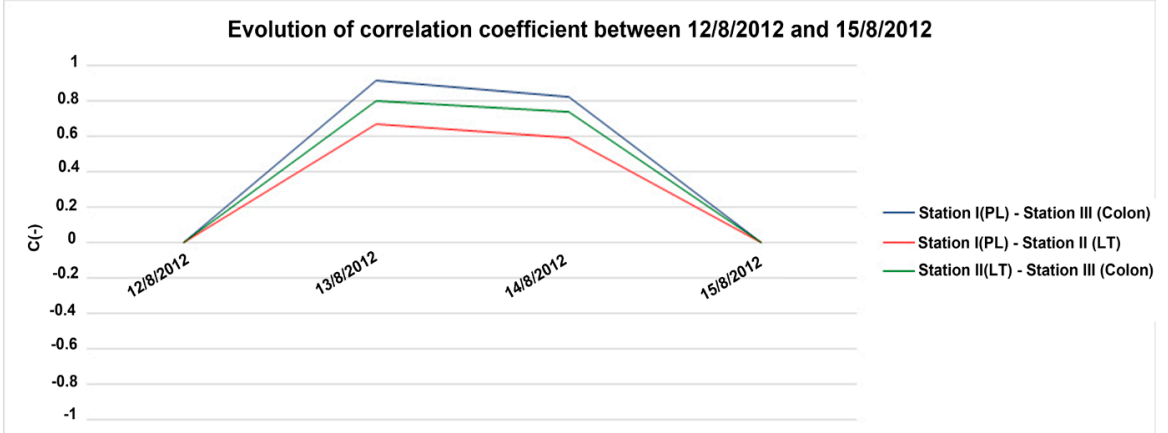

Figure 18. Time evolution of the correlation coefficients in the period between 12/8/2012 and 15/8/2012 (PL = Station I Palacio Legislativo; LT = Station II La Teja; Colón = Station III).

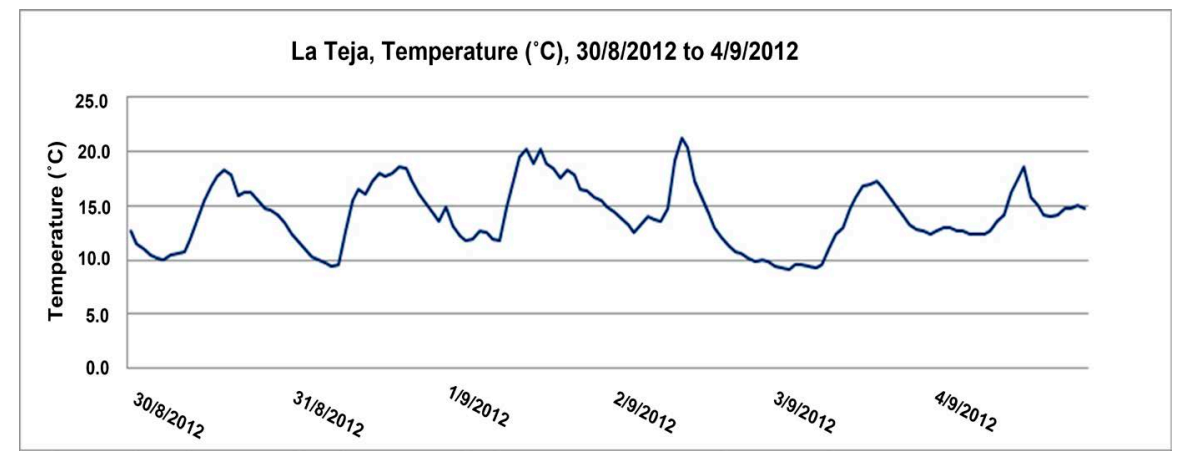

(a)

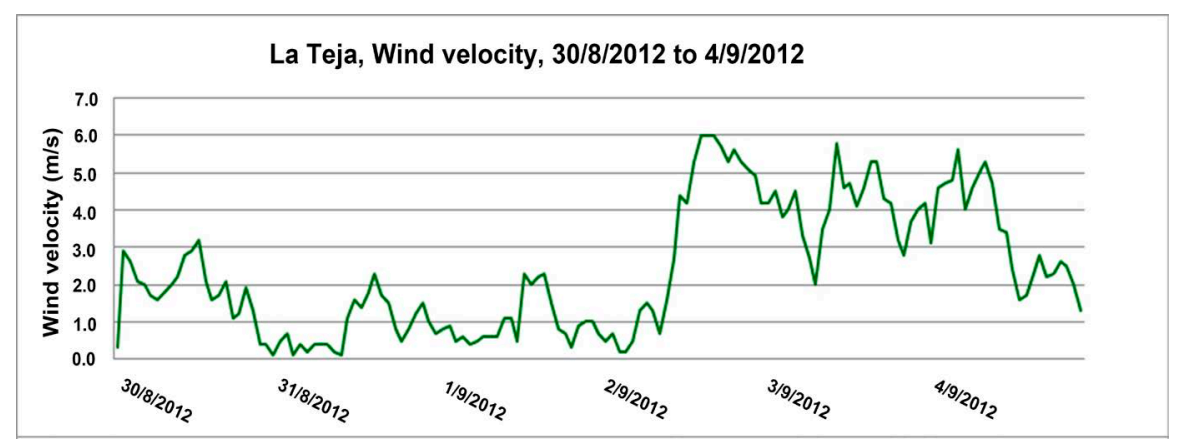

(b) 


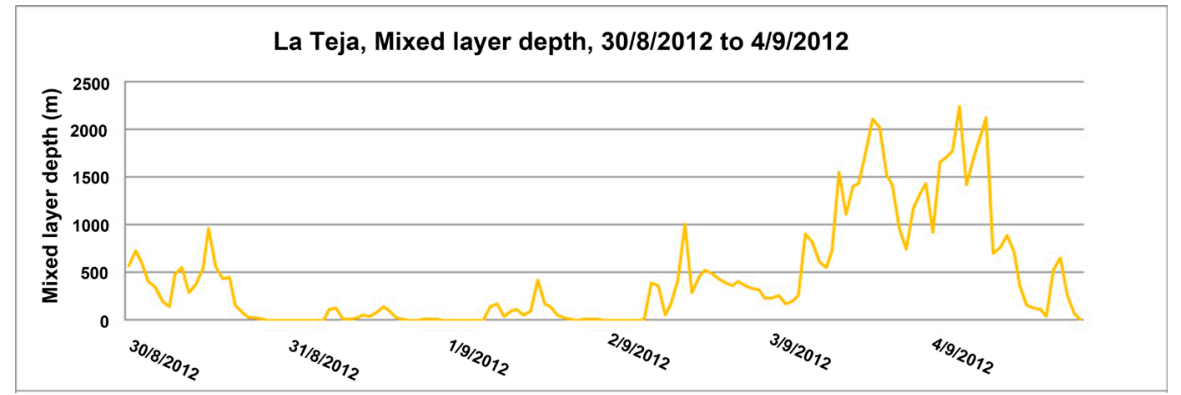

(c)

Figure 19. Time evolution of temperature, wind velocity and mixed layer depth during the event from $30 / 8 / 2012$ to $4 / 9 / 2012$.

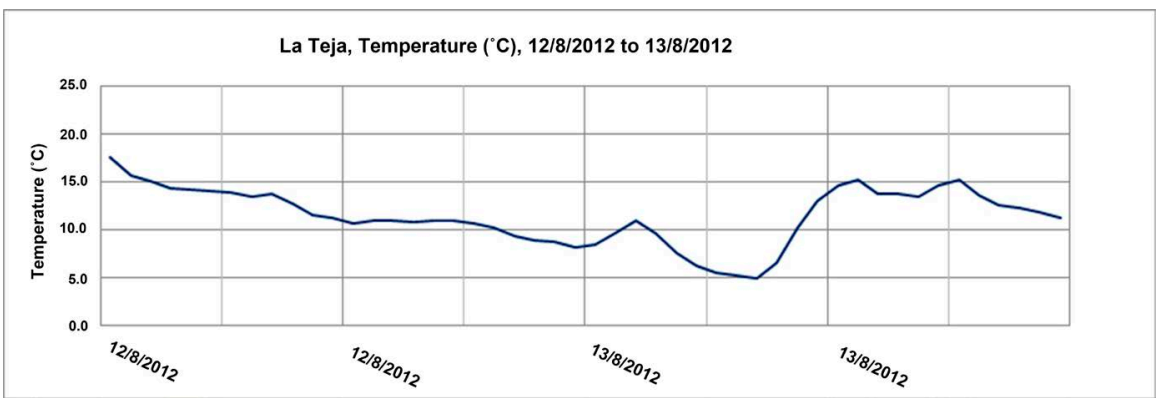

(a)

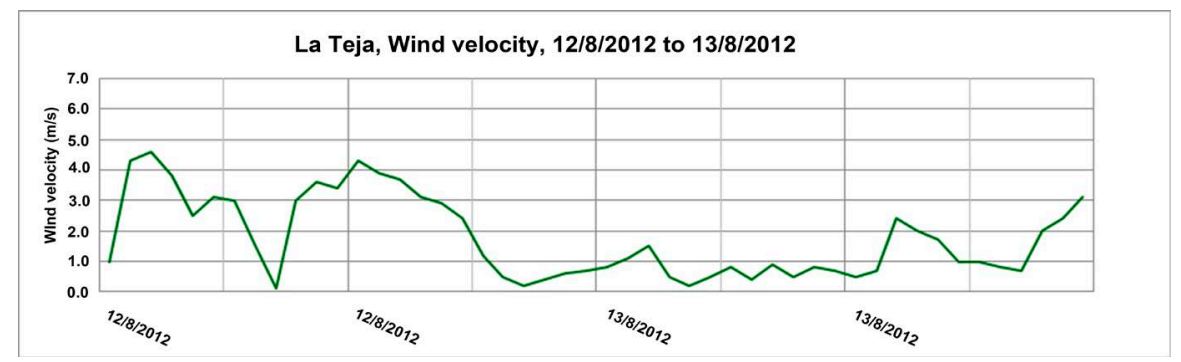

(b)

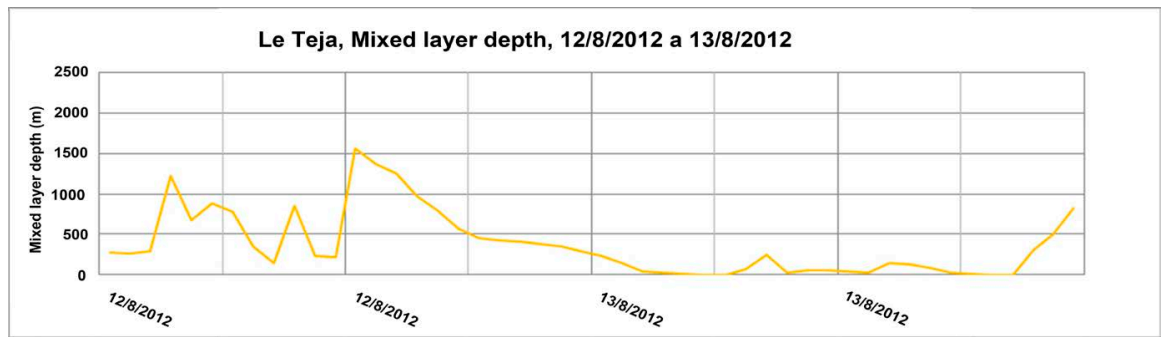

(c)

Figure 20. Time evolution of temperature, wind velocity and mixed layer depth along the event from 12/8/2012 to $13 / 8 / 2012$.

wood are burned for heating each year, mostly in a four to five months' period. This source releases more than 1500 ton of particles per year in the aforementioned period.

Additionally, when both the wind velocity and the mixed layer are low, very high particle concentrations are observed. From a meteorological point of view, 


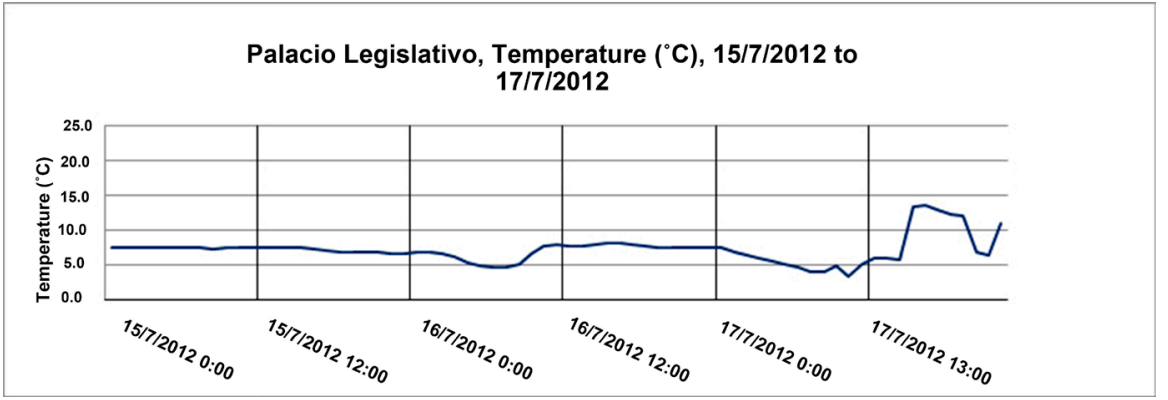

(a)

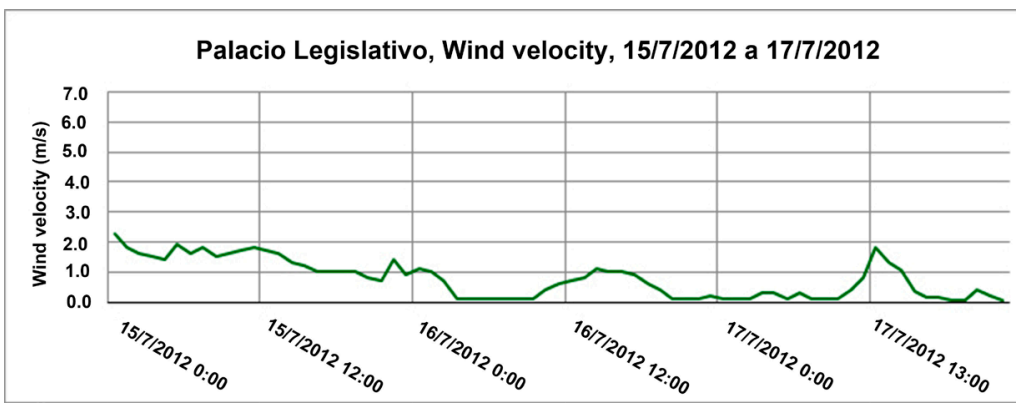

(b)

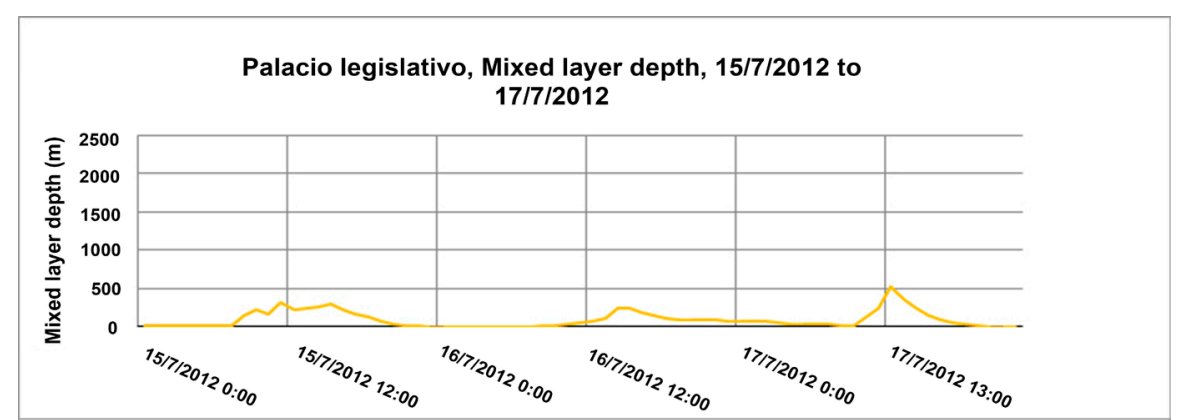

(c)

Figure 21. Time evolution of temperature, wind velocity and mixing layer depth along the events from $15 / 7 / 2012$ to $17 / 7 / 2012$.

the aforementioned meteorological events can be observed $0.5 \%$ to $1 \%$ of the time (that equals to 40 to 80 days per year).

\section{Conclusions}

To summarize the main issues of this paper, we present them into three main topics: climatology at Montevideo city; main meteorological parameters for atmospheric dispersion in urban environments; explanation of the generalized high MP concentration events and forecasting this kind of events.

\subsection{About climatology in Montevideo}

The climatology in Montevideo, as example case, was characterized with basis on the data obtained in the meteorological station of the International Airport of Carrasco, Montevideo Harbor and La Teja (Station II). The following are characteristics of the area: 
Table 5. Correlation coefficient along events with high particle concentration (Station $\mathrm{I}=$ PL Palacio Legislativo; Station II = LT La Teja; Station III = Colón).

\begin{tabular}{cccc}
\hline Date & \multicolumn{3}{c}{ Correlation coefficient } \\
\hline & $\begin{array}{c}\text { Station I-Station III } \\
(\text { PL_Colón) }\end{array}$ & $\begin{array}{c}\text { Station I-Station II } \\
(\text { PL-LT) }\end{array}$ & $\begin{array}{c}\text { Station III-Station II } \\
\text { (Colón-LT) }\end{array}$ \\
\hline $17 / 7 / 2017$ & 0.875 & 0.720 & 0.940 \\
$13 / 8 / 2017$ & 0.914 & 0.670 & 0.801 \\
$14 / 8 / 2017$ & 0.819 & 0.589 & 0.733 \\
$1 / 9 / 2017$ & 0.903 & 0.940 & 0.848 \\
$2 / 9 / 2017$ & 0.895 & 0.944 & 0.848 \\
$4 / 9 / 2017$ & 0.768 & 0.809 & 0.805 \\
\hline
\end{tabular}

- Higher frequency wind directions: NOREAST (23\%) and SOUTH (10\%).

- Annual mean velocities at an altitude of $10 \mathrm{~m}$ are between $2.7 \mathrm{~m} / \mathrm{s}$ and 4.8 $\mathrm{m} / \mathrm{s}$.

- Atmosphere STRONGLY STABLE or INVERSION during 30\% of the time.

- The mixing layer depth is at a high of $600 \mathrm{~m}$ during $53 \%$ of the time, while lower than $10 \mathrm{~m}$ during $4 \%$ of the time.

\subsection{About the Significant Meteorological Parameters}

The monitoring stations are located in different terrain types, with close and distributed pollutant sources as it is presented in Table 2.

From the analysis of the atmospheric dispersion processes, we identify as significant parameters:

- Wind direction. When the wind blows from the emission source to one monitoring station, the pollutants are transported in the direction of the wind and then they are detected in the station recordings.

- Wind velocity. Along the studied period, for low values of wind velocity, high pollutant concentrations are recorded, regardless the atmospheric stability.

- Mixing layer depth. This parameter is significant especially when low, high pollutant concentrations are recorded.

\subsection{About Explanation and Forecasting of This Kind of Poor Air Quality Events in Montevideo}

In all air quality monitoring stations, events with particle concentrations over the reference value are identified. These events have the following characteristics:

- A strong correlation between the concentrations is obtained at the three stations.

- High concentration of particles is present when the temperature is lower $13^{\circ} \mathrm{C}$.

- The period with high concentration occurs when wind velocity is lower than 
$3 \mathrm{~m} / \mathrm{s}$ and mixing layer depth is between $0 \mathrm{~m}$ and $10 \mathrm{~m}$.

As the behavior of the pollutant concentrations is associated to its emitting source, the main emitting source of particle matter is distributed all over the city and it is related to domestic heating by burning wood.

Therefore, this kind of poor air quality events could be forecasted just from meteorological forecasts.

According to our analysis, the forecasting of high particle concentrations related to domestic heating would be possible based on a climatic forecast, as they mainly depend on meteorological conditions.

Then, proper predictions about particle concentrations would be met through an accurate climatic forecasting model. As Montevideo air quality network is not operated in real time, this working way allows prediction of generalized unsettling air quality events expected to occur over the largest city in Uruguay. Both initial and operation/maintenance costs are lower for this option than for the simplest air quality monitoring network.

\section{Acknowledgements}

We are very thankful to National Directorate of Environment (DINAMA) from the Uruguayan Ministry of Housing, Territorial Management and Environment (MVOTMA) for its supporting of the research presented in this paper.

\section{References}

[1] Segura, S., Estellés, V., Esteve, A.R., Utrillas, M.P. and Martínez-Lozano, J.A. (2013) Analysis of Severe Pollution Episode in Valencia (Spain) and Its Effect on Ground Level Particulate Matter. Journal of Aerosol Science, 56, 41-52. https://doi.org/10.1016/j.jaerosci.2012.06.007

[2] Skamarock, W.C. and Coauthors (2008) A Description of the Advanced Research WRF Version 3. NCAR Technical Note NCAR/TN-475+STR.

[3] Grange, S.K., Salmond, J.A., Trompetter, W.J., Davy, P.K. and Ancelet, T. (2013) Effect of Atmospheric Stability on the Impact of Domestic Wood Combustion to Air Quality of Small Township in Winter. Atmospheric Environment, 70, 28-38. https://doi.org/10.1016/j.atmosenv.2012.12.047

[4] Dongerrà, G., Manno, E., Varrica, D., Lombardo, M. and Vultaggio, M. (2010) Study on Ambient Concentrations or $\mathrm{PM}_{10}, \mathrm{MP}_{10-2.5}, \mathrm{MP}_{2.5}$ and Gaseous Pollutants. Trace Elements and Chemical Speciation of Atmospheric Particle. Atmospheric Environment, 44, 5244-5257. https://doi.org/10.1016/j.atmosenv.2010.08.041

[5] Ahrens, C.D. (1999) Meteorology Today: An Introduction to Weather, Climate and the Environment. In: Cole, B., Ed., Thomson Learning.

[6] Arya, S.P. (1999) Air Pollution, Meteorology and Dispersion. Oxford University Press, New York.

[7] Plate, E. (1982) Engineering Meteorology: Fundamentals of Meteorology and Their Application to Problems in Environmental and Civil Engineering. Elsevier, New York.

[8] Gutiérrez, A., Cazes, G. and Cataldo, J. (2013) WRF-ARW Application to Forecasting Wind Energy, with Sensibility of Topography. International Conference on 
Wind Engineering, Porto Alegre.

[9] Pedlosky, J. (1987) Geophysical Fluid Dynamics. 2nd Edition, Springer, Berlin. https://doi.org/10.1007/978-1-4612-4650-3

[10] Holton, J.R. (2004) An Introduction to Dynamic Meteorology. Elsevier Academic Press, San Diego.

[11] Counihan, J. (1975) Adiabatic Atmospheric Boundary Layers: A Review and Analysis of Data from Period 1880-1972. Atmospheric Environment, 9, 871-905. https://doi.org/10.1016/0004-6981(75)90088-8

[12] Hunt, J.C.R. and Simpson, J.E. (1982) Atmospheric Boundary Layer over Nonhomogeneous Terrain. In: Plate, E., Ed., Engineering Meteorology, Elsevier, Amsterdam, 269-318.

[13] Lewis, J.L. (1995) The History behind Bower Ratio. Bulletin of the American Meteorological Society, 76, 2433-2443. https://doi.org/10.1175/1520-0477(1995)076<2433:TSBTBR>2.0.CO;2

[14] Kasten, F. and Gerhard, C. (1980) Solar and Terrestrial Radiation Dependent on the Amount and Type of Cloud. Solar Energy, 24, 177-189.

[15] Stull, R. (2003) An Introduction to Boundary Layer Meteorology. Kluwer Academic Publishers.

[16] GESTA Aire (2012) Propuesta estándares Calidad de Aire. COTAMA-GESTA Aire.

[17] EPA (2011) $\mathrm{PM}_{2.5}$ Modelling Implementation for Projects Subject to National Ambient Air Quality Demonstration Requirements Pursuant New Source Review. NACAA $\mathrm{PM}_{2.5}$ Modelling Implementation Workgroup, EPA.

[18] OMS (2005) Guías de la calidad del aire de la OMS relativas al material particulado, ozono, el dióxido de nitrógeno y el dióxido de azufre. Resumen de evaluación de los riesgos. Organización Mundial de la Salud.

[19] (2010) Inventario de Emisiones, Informe Final, Convenio MVOTMA-UDELAR. Instituto de Mecánica de los Fluidos e Ingeniería Ambiental, Facultad de Ingeneiría. 